\title{
Vicente Araguas, poética de enlace entre el realismo social y las innovaciones formales de los años 80 en la poesía gallega contemporánea
}

\author{
LUIS LUNA \\ UNED \\ luismiluna@yahoo.es \\ Recibido: febrero 2013. Aceptado: marzo 2013
}

\begin{abstract}
Resumen: La obra de Vicente Araguas es fundamental para desentrañar el paso de la estética del realismo social hacia las corrientes innovadoras de los años 80 del siglo XX en la poesía gallega contemporánea. En este artículo se hace un estudio pormenorizado de las características de su obra, incidiendo en los aspectos formales que documentan este vínculo. Además, se incide en la postergación de un autor afectado por la exotopía (término que se refiere aquí a aquellos escritores en una lengua $\mathrm{A}$ que viven en un territorio de lengua B) y que, normalmente, son rechazados por el canon de esa lengua A.
\end{abstract}

Palabras clave: Poesía, gallega, contemporánea, Araguas, exotopía, Grupo, Bilbao.

Resumo: A obra de Vicente Araguas é fundamental para desentrañar o paso da estética do realismo social cara ás correntes innovadoras dos anos 80 do século XX na poesía galega contemporánea. Neste artigo faise un estudo pormenorizado das características da súa obra, incidindo nos aspectos formais que documentan este vínculo. Ademais, incídese na postergación dun autor afectado pola exotopía (termo que se refire aquí a aqueles escritores nunha lingua A que viven nun territorio de lingua B) e que, normalmente, son rexeitados polo canon desa lingua A.

Palabras chave: Poesía, galega, contemporánea, Araguas, exotopía, Grupo, Bilbao.

\section{INTRODUCCIÓN}

«Agora que cío coa ollada no tempo, reparo en que levo feitas moitas cousas» (Araguas 2002:1) con estas palabras encabeza su autobiografía para la AELG Vicente Araguas (Xuvia-Neda (Coruña), 24 de septiembre de 1950) uno de los pioneros del Grupo Bilbao (Luna 2011: 285) y auténtico icono del movimiento gallego en Madrid. De acuerdo con él, su labor ha sido amplia, 
compleja y realmente interesante en el panorama de la escritura gallega contemporánea.

Esta labor comienza pronto, apenas con 18 años, cuando funda el grupo «Voces Ceibes», un conjunto de autores comprometidos con la lucha antifranquista y antirrepresiva que realizarán diversos proyectos conjuntos para conseguir la libertad y la democracia, amén de reivindicar la identidad gallega. Junto a él estuvieron Benedicto García Villar, Xavier del Valle, Guillermo Rojo, Xerardo Moscoso y Alfredo Conde. En distintas etapas tomaron parte también Miro Casabella, Xaime Barreiro Gil, Tino Álvarez, Suso Vaamonde y Bibiano Adonis Morón.

El colectivo se funda al calor del auge de la canción de autor en la península ibérica y más concretamente con los vientos de libertad que supone el concierto de Raimon en el estadio universitario de Santiago. Aquel concierto inicia la idea entre los jóvenes de crear un colectivo específicamente gallego, idea que se concretará en el primer concierto celebrado en abril del 68. Esta mítica fecha, que coincide con la desobediencia escenificada en Francia, asusta a un deteriorado régimen franquista, que decide iniciar una escalada de represión que no se detiene ni siquiera con la muerte del dictador. La represión se intensifica con el decreto del estado excepción del 69, que prohíbe los recitales y conciertos. El Grupo había ya grabado varios discos tanto colectivos como individuales y había conseguido actuar en Estudio Abierto, un popular programa de la televisión de entonces. Ese compromiso va a traer muchos problemas al poeta, que tendrá que abandonar en 1972 España, camino de Escocia, donde da clases de español, para ponerse a salvo de la dictadura y, tal vez, comenzar una nueva etapa.

Va a ser en el exilio escocés donde escribe su primer libro Paisaxe de Glasgow, que será publicado en 1978 por Pepe Cáccamo y Xosé María Álvarez Bláquez. Con este primer libro Araguas comienza una andadura que estará marcada por su residencia en Madrid, aspecto que, como veremos, tal vez marque cierta postergación (Frías 2010: 274) en cuanto al canon oficial de la poesía gallega. A pesar de esa dificultad, y también de su compromiso con la libertad y la identidad gallega que le granjeará algunas enemistades (Araguas 2002: 1), Araguas irá, libro tras libro -él mismo reconoce que la palabra poemario no es adecuada (Araguas 2002: 1)- consolidando una poética muy personal, donde el erotismo tiene una fuerte presencia (Palomares 2005: 97-105), además de una honda sinceridad y una fuerte trabazón entre lo personal y lo histórico. Su obra puede situarle estéticamente cercano a la denominada xeración dos oitenta que establece un rompimiento formal con la poesía inmediatamente anterior, instalada en los índices formales de la poesía social (Palomares 2005:98) si bien en el caso de nuestro poeta hay que hacer algunas consideraciones a esta afirmación, ya que nunca abandonará el compromiso con la realidad circundante tanto en su vertiente histórica, como en la político-social. Son precisamente estas consideraciones las que le hacen un actante fundamental en la poesía gallega contemporánea pues su poesía sirve de enlace entre las generaciones insertas en la poesía social y la renovación estética de $\operatorname{los} 80$. 


\section{LOS PRIMEROS LIBROS: PAISAXE DE GLASGOWY ÁS VECES EN DOMINGO ABONDA COA TENRURA}

El primer libro de nuestro poeta es casi una sorpresa para el mismo autor. Su exilio en Glasgow provoca que comience a escribir textos que en un principio no estaban destinados a ser poemas, sino, más bien, letras de canciones. Sin embargo el mismo autor cae pronto en la cuenta de que aquello está tomando cuerpo y relevancia, es decir, que tal vez se pueda tornar un libro (Araguas 2005: 10) como efectivamente ocurrirá algunos años después. Este primer volumen va a ser el comienzo de una manera particularísima de hacer su propia poesía, ajena además a los controles canónicos establecidos por el propio canon gallego, gracias a su residencia lejos de la tierra natal. Convendría tal vez el calificativo de outsider para una obra como la que estamos analizando, aunque este calificativo ha de esperar hasta las conclusiones de este artículo para poder afirmarse con rotundidad.

En este primer libro vamos a encontrar poemas de claro corte social, como el poema III o el XIX, centrados en la problemática por la que el poeta está transitando especialmente la Guerra Civil y las abundantes manifestaciones de finales del régimen. Pero, junto a ellos, aparecerán, textos con grandes innovaciones formales e imbuidos de una revolucionaria estética acorde con los poetas norteamericanos de la generación beat, tal y como se explicita en las citas y referencia del propio libro. Estas innovaciones formales, unidas al tema erótico, empiezan a desligarle de la estricta poesía social, si bien la problemática político-humanística no desaparece. Un poema insigne de esta manera de hacer será el VI:

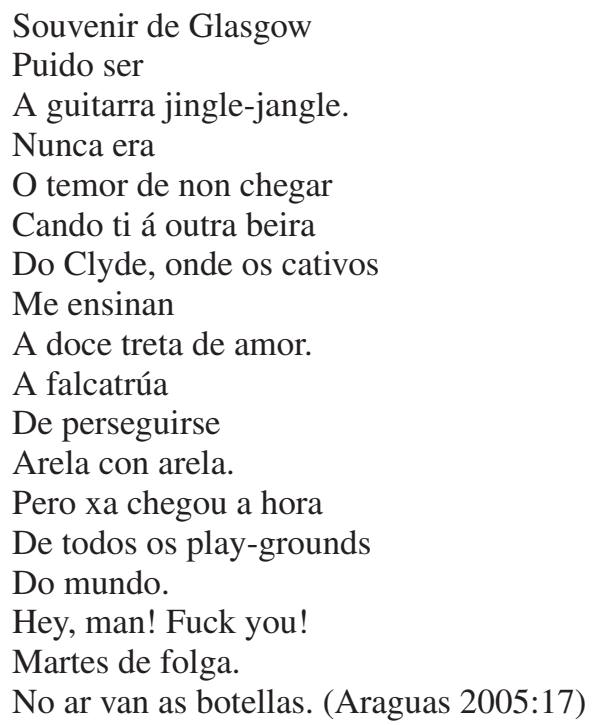

Como podemos observar, aquí se cruzan varios lenguajes, incluso varias lenguas. Lo reseñable es que este poema se publica en 1978, mucho antes de 
que ciertas innovaciones se introdujeran en la poesía gallega. Si tenemos en cuenta, además, que los primeros poemas de este libro datan del 72, podemos establecer que Araguas, influido por sus lecturas profundas de la poesía inglesa y norteamericana, es todo un pionero. Esta condición rupturista se completa también con un ingrediente básico de la poesía contemporánea, el humor. La ironía empleada por nuestro poeta va a asomar en casi todos los poemas del libro, configurando así un estilema fundamental de su poética. Junto a estas aportaciones seguimos encontrando la problemática social, esbozada en este poema mediante ese «martes de folga» que data la lucha presente también en Escocia.

Como vemos, se va conformando toda una forma de entender y de escribir poesía, precisamente con rasgos que luego serán medulares en lo que se vino a denominar Xeración dos oitenta o Promoción dos oitenta. Esta particular poética se explicita aún más en su siguiente libro Ás veces en domingo abonda coa tenrura. Este libro continúa con la expresión asombrada sobre la realidad que circunda al poeta en su devenir, en esa nueva etapa que va a ser Madrid, adonde se ha trasladado para conseguir un trabajo como profesor y alejarse de la represión en Galicia, puesto que ya se había granjeado enemigos suficientes como para instalarse allá. El libro se publica en 1980, año mítico en la capital que observa como todos los intentos artísticos que se venían produciendo desde los años 60 eclosionan en lo que luego se denominó la «movida» madrileña. Araguas participa en la mítica revista Loia junto a autores de la talla de Manuel Rivas o Lois Pereiro.

Nuestro autor se va a fijar en pequeños detalles que le sirven para entretejer su intrahistoria a la historia social de su tiempo. Va a ser este trabajo el que nos permita afirmar que Araguas es un autor de una radical modernidad, además de servir de enlace entre tendencias, ya que consigue aunar poesía comprometida con una fuerte labor de exploración en el lenguaje, construyendo una estética muy exigente. Se trata de observar pues unas características que conformarán la poética del autor, sus estilemas, pero también de observar la capacidad de reinvención en cada libro, lo cual permite una vigencia de su poesía que otros compañeros de generación no han conservado. Para observar esa vigencia cabe traer aquí un poema de As veces que podría firmarse hoy por cualquier poeta joven:

\section{Bairro da Prosperidá:}

De bubelas pousadas nos carteis de pisquitos, forte o cheiro familiar de metro, a incensó no periquito do estrondo e nenos comenzaban o charivari. Nas escaleiras mecánicas ti e ti galega de silveiras e arredores da praia de Caveiro aínda este outono es ti; enxoito val de sorpresas que me desfás que, se cadra, te me apegas como as lapas da bombilla pobre do colchón ao sol de aceite na hora do espertar, meu amor, o sol de aceite porteiro alporizado guindándome do durmevela do entrechán. Acaso nos altos da Reverencia terás acougo. ¿SE SALIENTAR OU QUE CANTAROLA E MORRE HAI XA 3 ANOS? Amor, na praia de Caveiro todo é certo e todo se mergulla na sombra dos pardáis do río da mesa. Entón si. Agora....Agora tiñamos de baixar en Metro Carmen a penas Pueblo Nuevo. (Araguas 2005: 41) 
Esta vigencia va a continuar, como decíamos, a lo largo de todos los libros del autor. Sin embargo, conviene adentrarse más en cómo esa intrahistoria se suma a la historia colectiva, provocando la reflexión y contribuyendo al cuestionamiento sobre la realidad. Los textos de Araguas, desde el principio, van a tender a poner sobre el tapete las complejas relaciones que se establecen entre sujeto y realidad, o lo que es lo mismo, la trama que se establece entre sujeto íntimo y sujeto social. A lo largo de toda su obra se advierte la sospecha, amalgamada con una gran dosis de humor, de que la sociedad es en realidad la suma de los individuos que la componen, siendo más importante la contribución a la colectividad de cada uno de esos individuos que la puesta en limpio, con sus aditamentos, supresiones e intereses, en la historia oficial. Se trata de configurar una adición de puntos de vista (o mejor points of view) que se traman de forma muy sutil para erguir lo que luego vamos a llamar realidad.

Parece fundamental deslindar aún más esa poética en los libros de nuestro autor, porque estamos hablando de que al articularse así, su poesía va a ejercer una labor pionera para los poetas que le siguen, especialmente en lo que se refiere a los poetas de expresión gallega en Madrid ya que, como veremos, la obra de Vicente Araguas se ve fuertemente afectada por la exotopía (Frías 2011: 274) $\mathrm{y}$ va a verse postergada en el canon gallego.

\section{LOS POEMARIOS DE LOS AÑOS 80}

La década de los 80 se había iniciado para Araguas con un poemario de llegada a Madrid y de cierre de su etapa anterior en Glasgow. Hemos visto cómo ese poemario deja muy a las claras la poética en embrión que luego se va a desarrollar y antepone la trabazón de la intrahistoria con la historia social como elemento básico de pensamiento. Araguas va a participar también, activamente, en la cultura gallega de la capital (Acuña 2009:455). Esta participación va a contrastar con la difusión que se hace de su propia poesía en Galicia en la que ha pasado desapercibida. Esa postergación que ofrece al mismo tiempo cierta libertad, permite al poeta hacer un libro tan a priori personal como Poemas pra Ana Andrea, dedicado a su hija, concebida en Edimburgo.

La tirada del libro es escasa, como indica el mismo autor en su prólogo (Araguas 2005: 61) solo 200 ejemplares que quieren precisamente acercarse a los más allegados al poeta. Se trata casi de un código secreto, familiar, que no resiste una lectura profunda del libro. Enseguida nos damos cuenta de que la estética del poeta rezuma en los textos y es allí donde el libro se hace universal en la experiencia de la paternidad. Y también descubrimos ese mezcla de lo personal con lo social desde el primer poema:

Folga de taxis madrís, useras, iglesias

Ana agora si luchana

paisaxe teu

agora si meu ben 
recolle ti la española

arxentinos a moreas

libros teus

xoves de outono

xardy, sinusitis, Wellington

xa de vacacións filmes dos cataláns mal traducidos. (Araguas 2005: 63)

Lo primero que llama la atención del estudioso es la absoluta falta de signos de puntuación en el texto, lo cual hace que cada lector deba puntuar a su gusto para encontrar su propio poema. Esta disposición formal, reforzada por la ausencia de mayúsculas, provoca ya una impresión de modernidad centrada en el urbanismo y la cotidianidad, lo cual acerca a Vicente Araguas a las denominadas corrientes existenciales, si bien, en el caso de nuestro poeta matizadas por una más que correcta asimilación de las poéticas beat y del neofolk. Esta mezcla, que no niega las libertades formales, algo que sí preconiza la vertiente existencialista hispánica (o poesía de la experiencia) será uno de sus rasgos diferenciadores y más interesantes. Con estos mimbres construye Araguas una poesía íntima pero no intimista. No hay sentimentalismo forzado, ni juicios de valor en su poesía; hay duda sobre el lenguaje, sobre el código y hay, a la par un fuerte compromiso, como podemos ver en esa nueva referencia a la huelga que comienza el poema. Y todo ello con una enorme ironía que aumenta el distanciamiento y permite la entrada del lector en su propio texto.

Alrededor de ese intimidad orbitan también referencias culturalistas, guiños a lecturas, a películas, a la creación de una nueva mitología pertinente para el nuevo creador. Araguas contribuye, con su conocimiento de la literatura anglonorteamericana a la creación de ese emergente entramado de referencias vivenciales y culturales. Como vemos, estamos ante una obra compleja, que bajo una apariencia de sencillez, está intentando captar esa caótica realidad de todos los días, amansada por el reduccionismo y la aniquilación de las diferencias. Araguas es consciente del nacimiento de un nuevo ser, que va a ocupar su propio espacio y va a ser a su vez diferente de todos los demás. Interesa destacar esto porque la trayectoria del poeta tiene mucho que ver con el respeto y la defensa del diferente. Por ello vamos a encontrar también una nueva defensa de la lengua gallega en un texto aparentemente íntimo:

Un anda pola vida de poeta urbano

Sabes, Ana Andrea?

Eu non quixera dos caralletes

Clasificación nengunha

Pro teiman, tencionan, testimuñan

I eiqui me tes, vai túa.

Por iso, que na lingua que pra ti queremos

Non sabemos decir

Doutra maneira

Que vai onde vaia

Temos a casa chea de patucos perdidos. (Araguas 2005: 64) 
Menos íntimo, pero también de carácter cercano es su poemario Xuvia, muy importante en lo que a fijación de un particular idiolecto se refiere. En este libro Araguas fija definitivamente una manera de decir que lleva desarrollando desde sus tiempos de cantautor. Ese idiolecto va a tener varios rasgos claramente diferenciables:

- El juego del lenguaje es habitual. Las palabras pueden ser utilizadas como verbos, sustantivos, adjetivos, etc, perteneciendo como base a cualquier categoría gramatical.

- Hay creación de palabras en el sentido fuerte del término, es decir se utilizan palabras inventadas por el autor.

- Se utilizan en el mismo rango términos afectivos, familiares, científicos, urbanos y otros prestigiados por su uso poético habitual.

- El humor modifica fuertemente el código. La ironía se infiltra en cada palabra como una peculiar implicatura de la misma.

Además de la fijación de un código propio -algo básico para un poeta- se fijan otros aspectos interesantes, como los lugares que sirven de paisaje habitual en la obra, así Glasgow, Madrid y la tierra natal. Esos tres ejes van a ser los referenciales, entretejiéndose otros por superposición o contraste con ellos. Una vez creado ese mundo y habiéndolo dotado de un código propio, hay que señalar la realización de una particular mitología en donde se amalgaman héroes del cómic, referentes literarios, amigos trazados como figuras míticas o contramíticas, etc. Aspectos imprescindibles para los poetas de toda la península en el devenir de los años 80.

Veamos algunos ejemplos de lo que estamos estableciendo en los textos de este libro, así en su poema Xuviética (Araguas 2005:77):

\author{
Xuvia, Xuvenca, \\ Ás veces volta de calcetín, \\ Ou de tornelo, quizaves \\ Me solpendrín lendo de ti \\ En Henry James \\ E asubiabas; ¿femia? \\ No adro das maravillas. \\ O teu galán fun, o teu fillo, \\ O meu galano ti, \\ A miña noite de San Silvestre, \\ O meu caramelo de menta. \\ Ouh xuvenca Xuvia \\ Loia cotián de gurripatos \\ Como campás na zunia \\ Esculcándote vou mentras peneiro \\ Días raiados, días raiados, \\ Días raiados, días raiados.
}


Vemos aquí varios aspectos interesantes, en primer lugar la evocación del paisaje natal, de la infancia, pero de un modo poco habitual. Mientras que lo tópico hubiera sido un tratamiento melancólico, Araguas establece un distanciamiento de partida al introducir una especie de declinación de la palabra Xuvia, que se refuerza con la inclusión en el poema de términos poco o nada poéticos según la tradición como «tornelo»o «calcetín» e inmediatamente después una referencia a Henry James, nada inocente, pues bien sabido es que la técnica preferida por el escritor norteamericano era precisamente el «punto de vista» con insistencia en el drama psicológico y la alienación. El poema termina precisamente con esa evocación de la repetición, de la monotonía de los «días raiados» que consigue atrapar al lector en toda una serie de implicaciones sobre la existencia y su desarrollo, entre ellas si la infancia es realmente la edad de oro del ser. La existencia de una filosofía existencialista, que casa bien con el compromiso explícito de sus primeros tiempos, detrás de la poesía de Araguas se aprecia a cada paso. Precisamente, esta va a ser una de las causas por las que sus textos no pierden vigencia.

La década de los 80 va a terminar para el poeta con la publicación de Caleidoscopio en el año 88. Se trata de un libro que intenta recoger precisamente la realidad desdibujada por la memoria y el propio punto de vista con un tono melancólico. En él encontramos el texto «Oficio de vivir» que recoge algunas de las influencias literarias de nuestro autor, y las conjuga con su propia existencia, haciéndose partícipe de ellas mismas, reforzando el tono elegíaco puesto que todos los poetas incluidos son suicidas, lo cual podríamos considerar como un ejemplo de extratextualidad manifiestamente cómplice con el lector, pues conjuga la idea de que literatura y realidad van íntimamente unidas. En el territorio del poema, Araguas es el personaje fundamental sí, pero es ante todo un personaje en ese entramado ficcional que denominamos realidad, condicionado por nuestra propia percepción:

Zweig, Salgari, London,

Lucrecio, Héctor Quiroga, Lugones,

Séneca, Ganivet, Hemingway,

Chatterton, Manuel Acuña, Kawabata,

Nerval, Ferrater, Montherlant,

Jhon Kennedy Toole, Sá-Carneiro,

Vesteiro Torres, Larra, Virginia Woolf,

Koestler, Sócrates, Castelo Branco,

Fernández de la Vega, Mishima,

Antero de Quental, Malcom Lowry,

Maiakovski, Lucano, Felipe Trigo,

José Asunción Silva, Esenin,

Alfonsina Storni, Pavese, Petronio,

Sylvia Plath, Costafreda, José Mallorquí

e nós

ti

o mar

e min. (Araguas 2005: 113) 
Esa toma de postura, ese punto de vista del que venimos hablando se va haciendo cada vez más personal, más intensamente distinto y restrictivo, capaz de mantener su propia idiosincrasia incluso tras las sucesivas reinvenciones de su obra en cada nuevo poemario. Si algo puede afirmarse sobre Araguas con rotundidad es que estamos ante un poeta al que no se puede acusar de autocomplacencia. Habrá constantes sí, como venimos remarcando, pero siempre con algo nuevo, con algún matiz independiente de los anteriores. Así sucede cuando acabada la década de los 80 , tarde seis años en sacar un nuevo libro.

\section{LOS AÑOS 90, REINVENCIÓN Y CONSOLIDACIÓN}

Tras ese periodo de silencio aparece Campo Santo en 1994, un libro que incluye grabados del portugués Manuel Patinha. Estamos ante un libro muy breve y cuidado, que procura volver a coger el pulso de la tensión poética que caracteriza al autor. El tema central es el paso del tiempo y la ciclicidad de los eventos. Esta temática va a pasar a ser parte fundamental de nuestro autor a partir de este libro, como un índice de madurez y de reflexividad.

Esa reflexividad va a pasar también a su estética. Los poemas se ajustan a la página, e incluso se hacen más breves. Se condensa así la palabra poética, intentando expresar más con menos. También se advierte una preocupación por la imagen de una manera natural puesto que el poeta, al haber fijado su código, necesita necesariamente establecer relaciones propias entre esos elementos. No es de extrañar, en esa tesitura, que el recurso estrella de este libro sea precisamente la metáfora, explícitamente invocada en uno de los mejores textos del libro:

Galo da forxa

Vermella

Como a crista do galo

Para sempre

Así a luz

Que sae da forxa

E asulaga

Os campos de millo

Lá baixo na ribeira.

O cataventos

Vigoroso

De todos os veráns.

Os lanchóns

Da area.

O GALO DA FORXA COMO METÁFORA.

O GALO DA FORXA COMO METÁFORA. (Araguas 2005: 163) 
Esta reivindicación de la metáfora, del símbolo como puntal fundamental de lo poético va a realizarse en su siguiente libro de modo explícito y continuista con el texto reproducido anteriormente, ya que $O$ Gato Branco (1995) será un libro señero en la producción de nuestro autor y marcará la más reciente forma de hacer de nuestro poeta. Vitalmente, el libro supone también la forja del Grupo Bilbao, ya que será en su presentación, según casi todos los testimonios (Acuña 2009, 467-477) donde se desarrolla la idea de agruparse en torno a la lengua y la creación gallega desde Madrid. El Grupo Bilbao significará para Araguas un punto de inflexión ya que a su través, y al de las tertulias realizadas en el café Comercial de Madrid, su poética, su enseñanza de una forma de hacer poesía llegará a autores jóvenes residentes o de paso por Madrid. Araguas es un poeta maduro, con capacidad para transmitir sus opiniones y reflexiones sobre un modo especialísimo de hacer y concebir la palabra poética.

En el grupo también encontrará a poetas con los que departir y sentirse arropado, toda vez que habita un espacio que no facilita el empleo y el uso de la lengua gallega en la vida diaria. Allí coincidirán Manuel Pereira, Xavier Frías, Inés Canosa, Ráfa Yáñez y casi todos los actantes de la vida artística gallega en Madrid. No es este espacio para poner de relieve la valía y vigencia del grupo y las tertulias pero cabe destacar el destacado papel que va a ejercer dentro del propio desarrollo de la literatura gallega, poco reconocido dentro del ámbito de la crítica. Así lo ponen de relieve los mismos autores y algunos estudiosos, especializados en los grupos literarios gallegos y de expresión gallega fuera de las fronteras administrativas de Galicia (Acuña 2009: 467-477).

Junto a ellos, como decíamos, comienza una nueva etapa, marcada por la publicación de $O$ gato branco, que se va a convertir, además, en su último poemario de esta década. Si con el anterior texto el autor había entrado con fuerza en la interdisciplinariedad propia de esos momentos y había aportado un nuevo impulso centrado en la metáfora a su poética, el nuevo libro va a centrar la temática para poder explorarla desde diversos ángulos. Aquí se produce un tema principal (el eros) y se establecen variaciones. Estas variaciones hacen hincapié, ante todo, en la abolición del tiempo lineal. Los recuerdos, las evocaciones, toman la misma relevancia que los sucesos actuales y suceden al mismo tiempo. Ese suceder, ese tratamiento del tiempo va a ser tal vez uno de los aspectos formales más interesantes del libro, pues pasa a trabajar entonces en el territorio de la memoria, donde la coordenada temporal se diluye. Al mismo tiempo y por necesidad de la propia temática del libro, la coordinación entre existencia íntima y existencia social va a desaparecer. Hay referencias, sí, pero son propias de la situación de los poemas, sin intentar tramar una relación necesaria, como habíamos visto en los anteriores textos. El eros exige la total desaparición de lo residual, de lo otro, pues para la plenitud de los amantes no importa otra cosa que los amantes mismos y el acto de su propio amor.

El escenario de estos textos tiene que ver con lugares de tránsito (trenes, hoteles, etc) que prefiguran la imposibilidad de esa plenitud y crean el conflicto 
propicio para las variaciones que se van a ir sucediendo. Veamos una de esas variaciones:

\author{
ADEUS E BOA SORTE \\ Eis o tempo \\ Máis duro \\ Cando un deles \\ Ameaza \\ - ¿quen tivo \\ A culpa? \\ Ningún dos dous \\ Se cadra- \\ Con irse. \\ A tarde no espello, \\ A louza non chineiro \\ Saben \\ A marcha. \\ Pero non, \\ aínda é cedo \\ se eles pronuncian \\ a palabra. \\ (Ai, amor, \\ No faiado \\ Hai unha chea \\ De verbas máxicas. (Araguas 2005: 195)
}

Como vemos, lo conversacional se hace explícito y el eros se hace central pero hay un detalle fundamental que encumbra la anécdota hasta convertirla en poesía y es precisamente el tratamiento y uso de la narratividad, al tiempo que la necesaria fragmentación para que el libro no se convierta en una novela troceada. La historia que se desarrolla está en todo momento relacionada con los amantes si bien, como ya hemos referido no hay una linealidad, sino más bien una suma de digresiones de carácter proustiano. Esa historia además se recupera en función de fragmentos, algunos importantes desde el punto de vista formal, especialmente el inicio y el fin, y otros irrelevantes desde el punto de vista narrativo, pero fundamentales en lo poético, pues permiten al lector reconstruir a su propio modo y en su propia conveniencia lo puesto en claro por el escritor. El texto se convierte así en un manuscrito lleno de lagunas que solo el lector debe reconstruir. Al hacerlo así, la historia queda trascendida en función de su propio simbolismo.

No hay duda de que el autor conoce bien los recursos poéticos y que los utiliza para reinventarse y dotar a sus libros de una cercanía, de una aparente sencillez que sin embargo está bien meditada y montada para lograr que el lector se conmueva y dote de sus propias intenciones al texto. Demuestra, por tanto, una madurez plena sin que por ello los textos pierdan un ápice de frescura. Un delicado equilibrio entre cercanía y recursos literarios hace que el libro se sostenga y pueda aportarnos verdadero lirismo que, en algunos momentos, es muy intenso. 


\section{LOS 2000, LA CONSOLIDACIÓN DE UN MAESTRO}

El año 2000 significa para nuestro autor la publicación de Río Matinal, un libro donde los textos dispuestos versicularmente alternan con las prosas poéticas. Estas últimas habían sido desarrolladas de manera muy esporádica en los anteriores libros del autor si bien con singular acierto puesto que incorporan innovaciones formales tramadas magníficamente con el resto del texto. Ahora se nos van a ofrecer en una serie titulada «Despois da paisaxe» y demuestran muy a las claras el conocimiento del uso de esta singular forma poética. En Araguas la prosa poética va a ser el vehículo lógico para una narratividad diluida en fragmentos. La serie se centra en varias sucesos, ocurridos todos ellos en años distintos, pero con el enganche del punto de vista de la voz que cuenta. Se trata, entonces de seguir desarrollando el especial point of view del que hablábamos anteriormente, pero haciendo que el tiempo se pliegue y se repliegue frente al observador.

Esta curiosa forma de evocación va a desarrollarse plenamente en el año 2004, un año importante en la obra de nuestro autor, puesto que van a salir dos libros suyos, hecho destacable pues, en los últimos tiempos, hemos podido observar que se venían espaciando los tiempos de publicación. El primer libro publicado este año es Esquecín esquecer un texto donde todos los poemas van dedicados a personas importantes para nuestro autor. Es un libro homenaje, donde el autor quiere mostrar su pasión por la amistad, por coordinar esa intrahistoria con la historia social.

Una lectura superficial podría arrojar la impresión de que el libro recoge en realidad una serie de anécdotas poetizadas que sirven como presente para las personas a las que aprecia o con quienes tiene un vínculo relevante. Sin embargo, tenemos en realidad un álbum de fotos que revelan el entramado social y sentimental del poeta. El libro, en esa tesitura, no hace más que ahondar en la coherencia de la obra del autor. Desde esa coherencia es fácil explicitar que no es más importante la vida de un general, de un dictador o de un político. En realidad lo que más importa es la vida de cualquier ser, con su propia historia, sus propias impresiones y su propia forma de mirar. Si además ese ser es un poeta que incorpora en sí mismo las décadas más importantes para la puesta en marcha, la consolidación y la normalización de la creación en gallego no se puede más que insistir en el estudio profundo de estos poemas.

Por sus páginas desfilan Manuel Patinha, Manuel Pereira, Inés Canosa, Borobó...creadores y personas imprescindibles para todo aquel que desee internarse en la creación en gallego, especialmente en lo que se refiere a su desarrollo extraterritorial. Estos homenajes, fotografías de tiempos, hechos y lugares dejan entrever cierta nostalgia, cierta manera reflexiva, meditativa de pensar. La madurez y la experiencia vital se dejan ver en todos los textos:

Deléngome nas horas,

Vou debuxando os anos como lanchas

Para satisfacer

Estes instintos náuticos, 
Para sobrevivir

Ao xeito das gaivotas

Que van enchendo os sitios

Onde anteriormente non había aves

Senón o rechouchío carismático

Das rapazas en flor.

Vaise poñendo a tarde

Por onde navegábamos

Cando a brisa mariña debe ser lenitivo

En tempos da miseria.

Vivir ás veces é boca de ría

Lenemente artillada,

Un enxamio de corpos

Que non consigo recordar agora.

Recóllome nas ondas

Suntuosas, non reparo

Aínda na desfeita do tempo.

Entendo como propio

Este tributo da beleza,

Ese ruxir no corazón,

Que se chama Eva, mais nós dicímoslle Pecado. (Araguas 2005: 248-249)

Este tono melancólico se va a tornar elegíaco en Vintecatro maneiras de querer a Brian escrito en memoria de Brian Peter Hughes, gran amigo del poeta desde su exilio en Glasgow. A través de los textos del libro encontramos nuevos indicios de la geografía vital de Araguas, de sus andanzas y reflexiones. La amistad va a ser el andamio que sujeta el entramado del réquiem. Una amistad forjada en torno a conversaciones regadas con distintos alcoholes, instantáneas de aquí y de allá y algunas lecturas. Araguas profundiza en su característico tono íntimo, lleno de humor y sinceridad. En este breve libro encontramos compendiadas y reforzadas las características que hemos venido esbozando a lo largo de todo este estudio: intimidad, compromiso, humor, erotismo, etc. Tal vez un poema esencial para comprender al Araguas maduro, maestro ya en técnica y composición del poema sea el XXIII:

A estas alturas da película

¿a cales, Brian, que me vou perdendo?

A estas alturas, digo,

Do monólogo que te busca

Tan retórico que nin resposta agarda

Nin un pouco roibén por parte nosa.

A estas alturas xa todos sabemos

Que tomaches porta ao xeito francés,

$\mathrm{O}$ que non encaixa coas boas maneiras

Do neno caledónico que tiñas.

Unha figa sumptuosa

Esa que nos ceibaches, 
Aquela noite de outono

Con cara e voz de queixo,

Con rostro de lúa prendida

E mans de doncela escolástica.

A estas alturas da película

A cousa semella un malentendu

Coma cando aquela señora belga

Pedía que lle coidases a filla

Nunha xornada fría e ferroviaria

Atal a madrugada que nos deixas.

A estas alturas da vidiña

Vou mirar sen ver no patio de luces

Vou poner a lapis un ceo de loito

Na paisaxe eternamente gris de Glasgow. (Araguas 2005: 270)

Esa misma madurez nos va a asaltar en el último libro de poemas de Araguas hasta el momento, Xuvia revisitada. Cuatro años de diferencia con el anterior libro, veinticinco de distancia con su inicial Xuvia. Esta revisitación de los paisajes (geográficos y sentimentales) de la tierra natal viene a ser una suerte de retorno, de explicitación de esa ciclicidad que se desarrolla en la poesía de Araguas desde los años 90 . Un ciclo se ha cumplido y el poeta siente la necesidad no solo de hacer referencia a su propia historia, sino también a la de su obra. De ese modo, la trabazón entre historia íntima e historia social se ha completado mediante la poesía, como si este fuera el vínculo más fuerte. Después de todo, ¿qué sucede si alguien no lo cuenta? Esta es la máxima que parece subyacer en un libro, donde además, se recupera el compromiso explícito de los primeros tiempos de la obra de Araguas. De ese modo, su memoria nos es indispensable, sus fragmentos son imprescindibles para la reconstrucción de una historia que es de todos, y no solo de los personajes que alguien decidió que eran más relevantes:

Nesta habitación do teito tan alto

Como os supiros das rapazas que nos quixeron

Como o sol de metade de verán

Repitíndose nun río marchoso.

Nesta casa de vivos onde vamos tan firmes

Porque somos pasado que non desexa arder,

Periquitos de montes,

Espadas con que amar.

Neste rostro perplexo cando tantas preguntas

Nin siquera son nosas

Senón os teitos altos

Da casa que nos leva, corazón do verán. (Araguas 2008: 34)

El libro se desarrolla pues en un tono conocido por nosotros, dando muestra de lo que es capaz un poeta en su máximo de creación, y al que todavía le quedan muchos libros por escribir, si tenemos en cuenta su edad. 


\section{EXOTOPÍA Y POSTERGACIÓN}

Antes de iniciar las conclusiones de este artículo debemos hablar de la exotopía que afecta a Vicente Araguas por su residencia en Madrid, lejos de los círculos habituales de la literatura gallega. El fenómeno de la exotopía ha sido bien estudiado en la literatura que nos ocupa (Luna 2011:284) y resulta especialmente pertinente a la hora de hablar de Vicente Araguas.

A lo largo del estudio sobre su obra hemos podido apreciar la calidad de sus poemas, la rotundidad de su poética y también la extensión en el tiempo de la misma. A estos datos, hay que añadir que Araguas es, además, un destacado columnista de prensa y que en los últimos tiempos ha conseguido publicar en editoriales canónicas dentro del ámbito gallego como Espiral Maior. También la crítica universitaria, especialmente la dedicada a la literatura gallega en Madrid, ha resaltado los valores de su poesía. Además, está incluido en las antologías más exigentes de poesía gallega y en algunas de carácter internacional.

Estos índices deberían bastarnos para afirmar sin duda alguna su inclusión en el canon y su consiguiente repercusión en la literatura gallega. Y sin embargo, no es así, lo cual incide en una postergación en la que han insistido algunos estudios, así Xavier Frías (Frías 2011:275) se pregunta si la canonización pasa por vivir en Galicia, a lo que habría que añadir si además de vivir en Galicia hay que pertenecer u orbitar alrededor de los propios círculos de escritores gallegos. Vicente Araguas siempre ha sido independiente, realiza su obra con sus propios tiempos, manejando su poética de forma libérrima y sin plegarse a las exigencias de ese canon. Por ello, su postergación es manifiesta. Él mismo lo advierte en algunos de sus artículos, como el que señalamos al principio de este estudio. Es conveniente realizar este somero repaso, pues indica cómo fenómenos extraliterarios inciden, en numerosas ocasiones en la recepción y aprecio de poetas excelentes.

\section{CONCLUSIONES}

A lo largo de este estudio hemos estudiado en toda la profundidad que ha sido posible la poética de Vicente Araguas, uno de los poetas más destacados de las últimas décadas de la poesía gallega. Su obra es sin duda una de las más complejas, profundas y enriquecedoras de los últimos años, pues explicita el compromiso contemporáneo con la realidad circundante y el entramado con el peculiar imaginario íntimo y punto de vista del poeta. La calidad de esa mirada está fuera de toda duda. Araguas es un depósito vivo de la memoria de este país y su independencia, honestidad y claridad así nos lo demuestran si bien, como hemos señalado, está afectado por la exotopía lo cual incide en cierta postergación o relegamiento.

Sus libros, más de una docena, van conformando ciertos rasgos propios, rasgos de estilo que nos inducen a pensar en Araguas como un poeta de enlace entre el compromiso social propio de los años 70, las innovaciones de los 
años 80, la individualización de los 90 y la reinvención y atomización de los 2000. En Araguas destacan:

a) Un intenso compromiso con la sociedad. Primero de una manera explícita, después tramando fuertemente la historia íntima con la historia social

b) Un destacado trabajo de lenguaje que se interna en las innovaciones formales de las vanguardias, incluyendo además, la tradición inglesa y norteamericana en su poesía

c) La presencia de una fuerte ironía como método de distanciamiento.

d) La temática amorosa, reflejada en casi todas sus vertientes.

e) Cierto tono reflexivo y melancólico en sus obras de madurez.

f) Creación de un especial idiolecto formado por términos restrictivos que incluyen neologismos, extranjerismos, dialectalismos, etc

Estas son las características que hemos resaltado a lo largo de todo el artículo, poniendo de manifiesto el dominio de la palabra poética por el poeta, especialmente en su madurez, donde los poemas dan lo mejor de sí mismo. En esta tesitura, es preciso afirmar para concluir que la voz de Araguas es esencial dentro de la poesía gallega, más allá de cánones, lugares de residencia u otros factores extraliterarios.

\section{BIBLIOGRAFÍA}

Acuña, A. (2009) Facer literatura galega en Madrid (1950-2000), Santiago de Compostela, USC.

Araguas, V. (2005) Maneiras de querer. Obra Poética (1978-2005), A Coruña, Espiral Maior.

- (2008) Xuvia revisitada, Ferrol, Esquío.

Frías, X. (2011) «Os 15 anos do Grupo Blbao:algunas reflexións», RLLCGV, XVII, pp.273-282

Luna, L. (2011) «A colección $O$ Roibén, vieiro de expresión poética do Grupo Bibao», RLLCGV, XVII, pp.283-296.

Palomares, V. (2005) «El amor en la poética de Vicente Araguas: Paisaxe deGlasgow, Ás veces en domingo abonda coa tenrura y O gato Branco», Madrygal, 8, pp. 97-105.

Web:

Araguas,V. (2002) «Autobiografía» en:http://www.aelg.org 